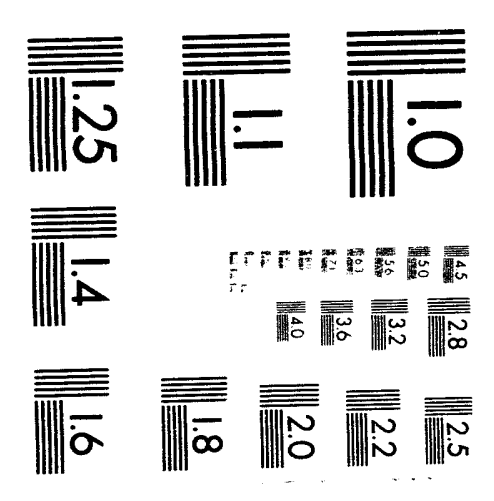




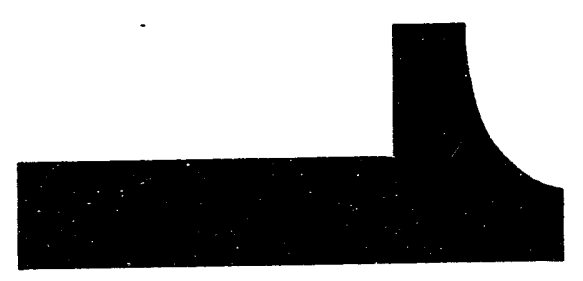




\title{
Quality Assurance Project Plan for Waste Tank Vapor Characterization
}

\author{
C. D. Suydam
}

Date Published

December 1993

Prepared for the U.S. Department of Energy Office of Environmental Restoration and Waste Management

\section{(W) Westinghouse P.O. Box 1970}

W Hanford Company Richland, Washington 99352

Hanford Operations and Engineering Contractor for the

U.S. Department of Energy under Contract DE-AC06-87RL10930 


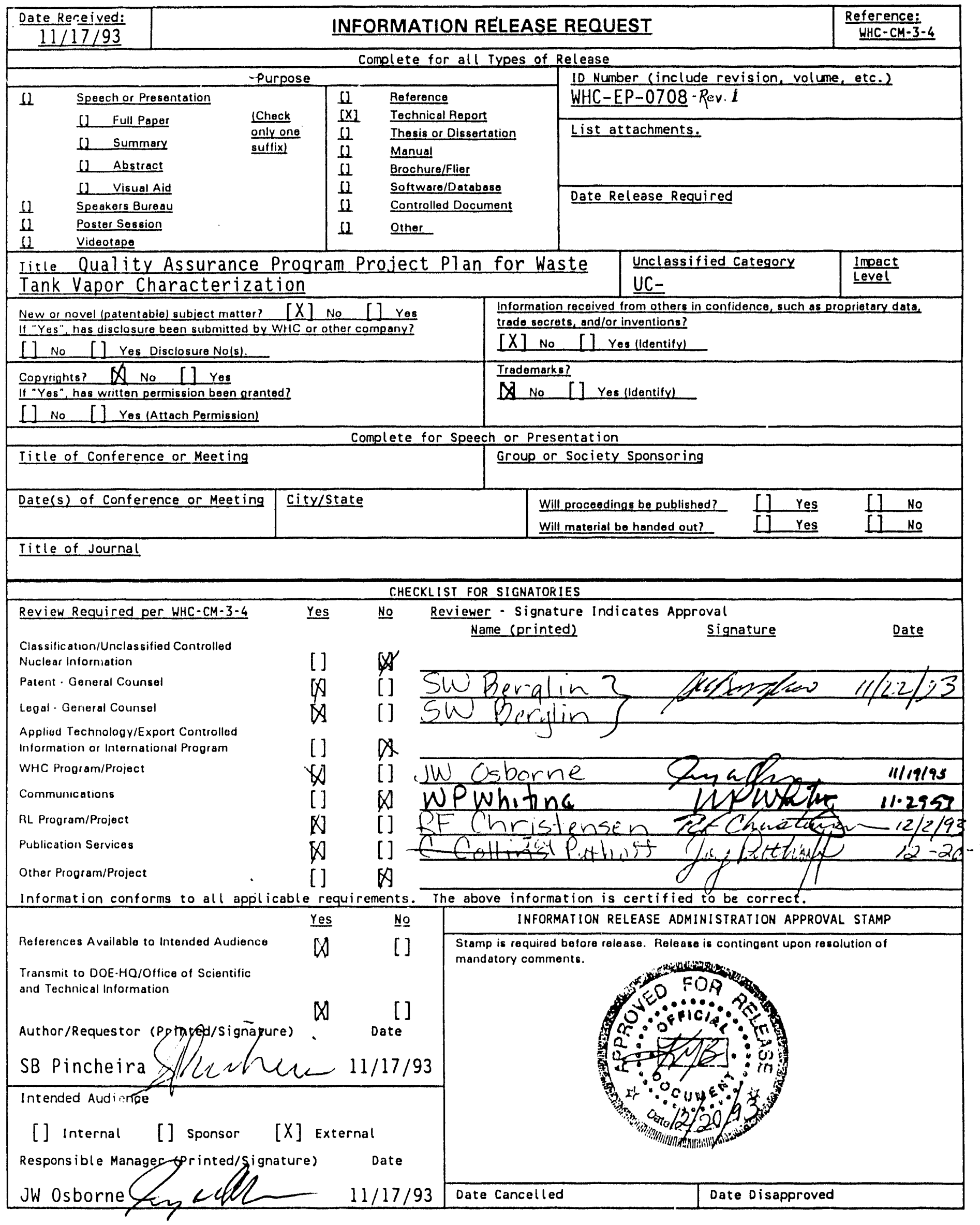


ID Number

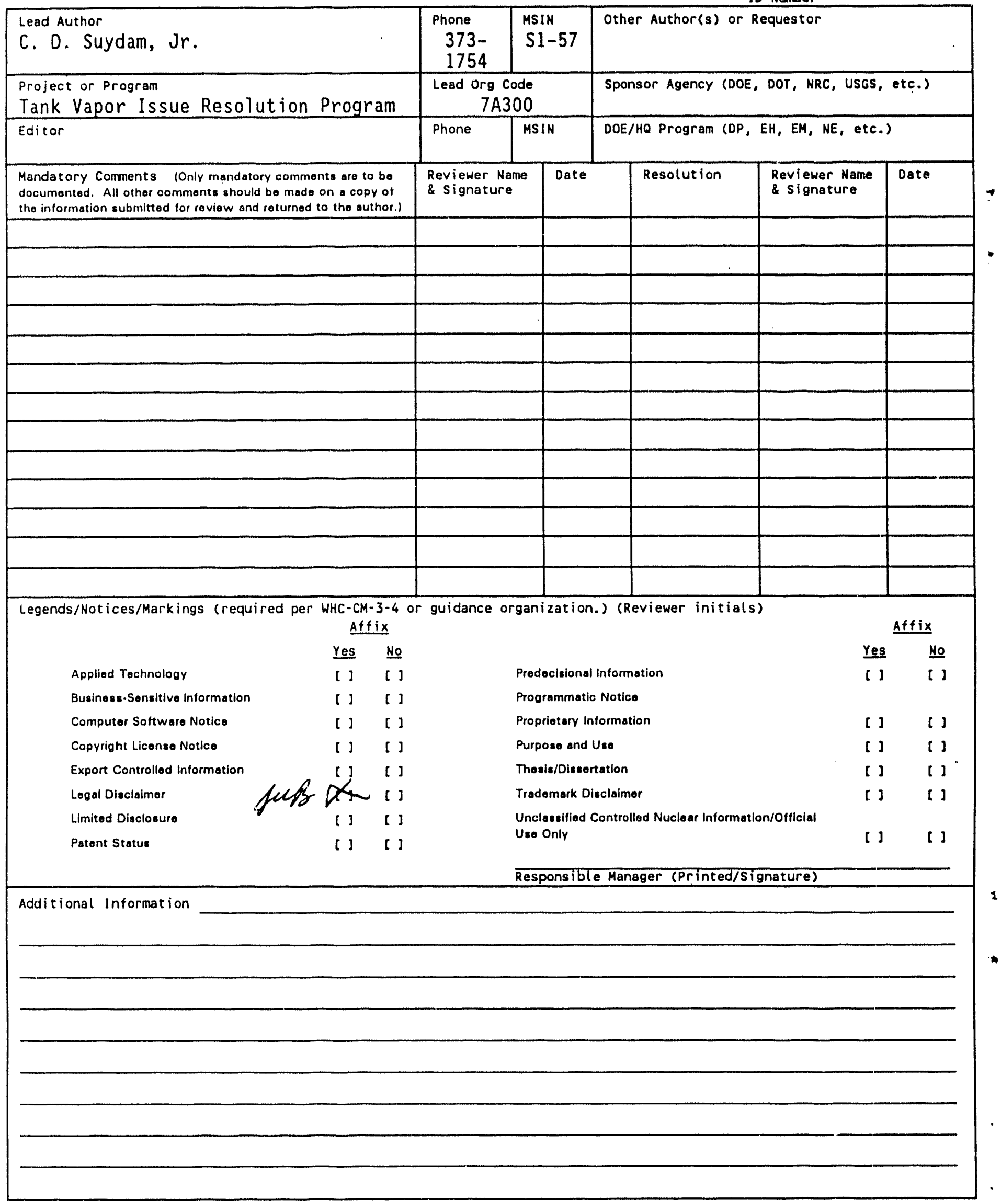


WHC-EP-0708 REV. 1

\section{EXECUTIVE SUMMARY}

This Quality Assurance Project Plan, WHC-SD-WM-QAPP-013, applies to four separate vapor sampling tasks associated with Phases 1 and 2 of the Tank Vapor Issue Resolution Program and support of the Rotary Mode Core Drilling Portable Exhauster Permit. These tasks focus on employee safety concerns and tank ventilation emission control design requirements.

Previous characterization efforts and studies are of insufficient accuracy to adequately define the problem. It is believed that the technology and maturity of sampling and analytical methods can be sufficiently developed to allow the characterization of the constituents of the tank vapor space.

The goals of this effort are as follows:

\section{Phase 1}

1. Identify analytes collected by the sampling systems and obtain rough quantitative data describing the constituents of the vapor space of tank 241-C-103.

2. Select the best sampling and analytical process/methodology for vapor characterization.

These will be accomplished through obtaining a better understanding of the tank vapor space by applying validated sampling/analytical procedures, 


\section{WHC-EP-0708 REV. 1}

identifying the performance (accuracy and precision) of those methods, understanding which of the methods are best applicable to the effort, and establishing the sampling protocol.

3. From the results of 1 . (above), and in consultation with the Tank Vapor Conference and the Toxicology Panel, revise the list of analytes of concern and analytes of interest for targeted analysis.

\section{Phase 2}

1. Fully characterize volatile components of concern and interest in the vapor phase of tank 241-C-103, both qualitatively and quantitatively.

2. Specify modifications to the characterization process/methodology that will allow the vapor spaces of all Hanford Site waste tanks to be characterized.

This will be accomplished by development of a sitewide vapor verification program, Tank Advisory Panel approval, and sufficient characterization of the tank vapor space contents (hazardous, flammable, and permanent gases/vapors) to permit the cost effective engineering of a mitigation or remediation system for tank 241-C-103. The Project shall apply validated vapor sampling and analytical procedures to specified waste tanks, and support the Rotary Mode Core Sampling program. This program requires the qualitative and quantitative characterization of analytes of concern and interest for the permitting of a portable exhauster to be operated during rotary mode core sampling. 
WHC-EP-0708 REV. 1

\section{CONTENTS}

1.0 INTRODUCTION . . . . . . . . . . . . . . . 1-1

2.0 PROJECT DESCRIPTION . . . . . . . . . . . . . . . . . 2-1

2.1 PROJECT TASK BREAKDOWN ................. . . 2-1

2.2 SAMPLE ANALYSIS TECHNOLOGIES ................ $2-1$

2.3 QA OVERSIGHT ................. . 2-2

3.0 PROJECT ORGANIZATION AND RESPONSIBILITY . . . . . . . . 3-1

3.1 WASTE TANK SAFETY PROGRAMS ............... 3-1

3.2 INDUSTRIAL HYGIENE AND SAFETY ........... $3-1$

3.3 WHC PROCESSING AND ANALYTICAL LABORATORIES (PAL) ...... $3-1$

$3.4325 / 329$ PNL ANALYTICAL LABORATORIES ........... $3-2$

3.5 OREGON GRADUATE INSTITUTE (OGI) ............ $3-2$

3.6 TANK FARMS OPERATIONS AND MAINTENANCE ......... . . 3-2

3.7 HEALTH PHYSICS ................. . . . . . . .

3.8 TWRS QUALITY ASSURANCE . . . . . . . . . . . . . $3-2$

3.9 ENVIRONMENTAL DIVISION . . . . . . . . . . . 3-3

4.0 QUALITY ASSURANCE OBJECTIVES FOR MEASUREMENT DATA . . . . . . . . . 4-1

4.1 INTRODUCTION . . . . . . . . . . . . . . 4-1

4.2 MINIMUM QUANTITATIVE LIMITS . . . . . . . . . . 4-2

4.3 PROCEDURE VALIDATION ............... . . 4-2

4.4 ACCURACY . . . . . . . . . . . . . . 4-4

4.5 PRECISION . . . . . . . . . . . . . . . . . 4-5

4.6 COMPLETENESS . . . . . . . . . . . . . . . . 4 4-5

4.7 REPRESENTATIVENESS . . . . . . . . . . . . . . 4-5

4.8 COMPARABILITY . . . . . . . . . . . . . . . . . . . . 4-6

5.0 VALIDATION OF PROSEDURES ............. . . . . .

5.1 ORGANIC ANALYSIS BY SUMMA CANISTER AND GC/MS OR GC/FID ... . 5-1

5.2 ORGANIC ANALYSIS BY DIRECT GC/FID ........... . 5-2

5.3 AMMONIA AND HCN BY BUBBLER AND SIE ........... 5-2

5.4 WATER BY SILICA SORPTION AND GAVIMETRY ........ $5-2$

5.5 TRITIUM BY SILICA SORPTION AND LIQUID SCINTILATION .... . 5-3

6.0 SAMPLING PROCEDURES AND SAMPLE PREPARATION ......... 6-1

6.1 INTRODUCTION . . . . . . . . . . . . . . . . . 6-1

6.2 CHAIN-OF-CUSTODY . . . . . . . . . . . . . . 6-1

6.3 FIELD BLANKS .................. . . . . . . . . .

7.0 CALIBRATION PROCEDURES AND FREQUENCY ........... . . . . .

8.0 ANALYTICAL PROCEDURES ................. . . . . . .

9.0 DATA REDUCTION, VALIDATION, AND REPORTING . . . . . . . . 9-1

9.1 DATA REDUCTION . . . . . . . . . . . . . . . 9-1

9.2 DATA VALIDATION ...................... . . . . . . . .

9.3 DATA REPORTING . . . . . . . . . . . . . . . . . . . . 9-1 
WHC-EP-0708 REV. 1

\section{CONTENTS (continued)}

10.0 INTERNAL QUALITY CHECKS AND CORRECTIVE ACTION . . . . . . . . 10-1 10.1 INTRODUCTION . . . . . . . . . . . . . . . . . . . 10-1 10.2 ACCURACY RELATED QC CRITERIA . . . . . . . . . . . . 10-1 10.3 PRECISION RELATED QC CRITERIA . . . . . . . . . . . . . 10-1 10.4 CONTAMINATION RELATED QC CRITERIA . . . . . . . . . . 10-3

11.0 PERFORMANCE AND SYSTEM AUDITS . . . . . . . . . . . . . . 11-1

12.0 PREVEnTAtive maintenance . . . . . . . . . . . . . . 12-1

13.0 QUALITY ASSURANCE REPORTS TO MANAGEMENT . . . . . . . . . . . 13-1 14.0 REFERENCES ........................ 14-1 
WHC-EP-0708 REV. 1

\section{LIST OF TABLES}

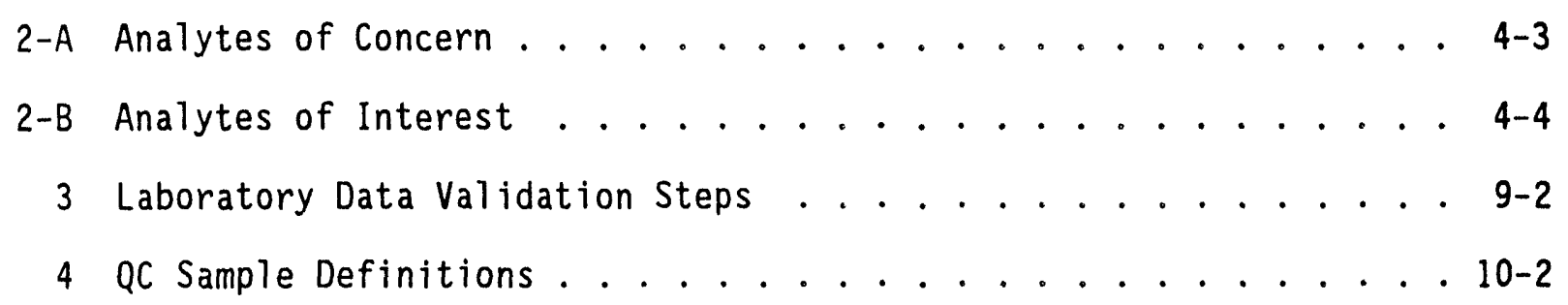


WHC-EP-0708 REV, 1

\section{LIST OF TERMS}

AMS

DOE

DQO

EPA

FID

$G C$

$G C / F I D$

GC/MS

GC/TC

IC

MSA

MS

MZG

NIOSH

NIST

OGI

PNL

$Q A$

QAM

QAPP

QC

RSD

Sandia NL

SIE

TLV/TWA

TQL

TWRS

WHC / PAL
Analytical Measurement System

U.S. Department of Energy

Data Quality Objectives

Environmental Protection Agency

Flame Ionization Detection

Gas Chromatography

Gas Chromatography/Flame Ionization Detection

Gas Chromatography/Mass Spectrometry

Gas Chromatography/Thermal Conductivity Detector

Ion Chromatography

Matrix Spike Addition

Mass Spectrometry

Moist Zero Gas

National Institute for Occupational Safety and Health

National Institute of Science and Technology

Oregon Craduate Institute

Pacific Northwest Laboratories

Quality Assurance

Qual ity Assurance Manual

Quality Assurance Project Plan

Quality Control

Relative Standard Deviation

Sandia National Laboratories

Specific Ion Electrode

Threshold Limit Value/Time Weighted Average

Target Quantitative Limit

Tank Waste Remediation System

Westinghouse Hanford Company/Processing and Analytical Laboratories 
WHC-EP-0708 REV. 1

\section{QUALITY ASSURANCE PROJECT PLAN FOR WASTE TANK VAPOR CHARACTERIZATION}

\subsection{INTRODUCTION}

This Quality Assurance Project Plan (QAPP) identifies procedures, describes applicable quality control (QC) and quality assurance (QA) methods, and documents information that will be used to support vapor sampling and analysis for the characterization of waste tank vapor spaces. The plan is limited to the developmental effort to accomplish objectives outlined in Section 2.0. Westinghouse Hanford impact level 3 SQ is assigned to this effort until the evaluation of the results indicates the need for another level.

Data quality objectives (DQO) are being developed to support the decisions to be made using the data obtained from this effort. These decisions involve the chemical constituents cuntained in waste tank vapor spaces, and will be developed from sampling efforts performed on tank 241-C-103. The objectives do not include establishing the mechanism of vapor formation and do not include the characterization of any medium other than the tank vapor space.

The initial objectives of Phase 1 will be to select the best process/methodology of tank vapor space characterization and to obtain preliminary measurements of the vapor space constituents in the specified tanks.

The ultimate objectives of Phase 2 are to establish a tank vapor space characterization program that can be applied to any Hanford Site waste tank and to characterize the vapor space of any waste tank. Included in this characterization will be an identification of flammability potential and a health hazard determination resulting from identification of toxic and/or noxious vapor and gaseous constituents. The details of the DQOS for the vapor space characterization effort are subject to evaluation and refinement. All numerical limits contained herein are tentative and subject to change. 
WHC-EP-0708 REV. 1

This page intentionally left blank. 
WHC-EP-0708 REV. 1

\subsection{PROJECT DESCRIPTION}

\subsection{PROJECT TASK BREAKDOWN}

The purpose of this document is to provide interim $Q A / Q C$ guidance for sampling and analyzing the vapor space according to the following tasks:

- Obtain triplicate SUMMA canister vapor samples for qualitative analysis of a specific set of organic analytes using a heated sample probe at a single level in tank 241-C-103 according to WHC-SD-WM-WP-198 (WHC, 1993).

- Obtain SUMMA canister and solid sorbent vapor samples for the develupment of quantitative analys is methods using a heated probe at each of three levels in tank 241-C-103 according to WHC-SD-WM-WP-223 (WHC, 1993).

- Sample and analyze the vapor in the tank C-103 according to WHC-SD-WM-WP-174 (WHC 1992).

\subsection{SAMPLE ANALYSIS TECHNOLOGIES}

In general, the samples taken from these tanks will be analyzed under the $Q A / Q C$ requirements described in this document. The effort will involve the use of four independent sampling and analysis techniques in Phases 1 and 2 . These techniques are:

- SUMMA ${ }^{1}$ canister sampling fol 'owed by $G C / M S^{2}$ or $G C / F I D^{3}$ organic analys is

- Sorbent Tubes ${ }^{4}$

- GC/FID or GC/TC organic vapor space analysis either (1) after direct sampling or (2) solid sorbent sampling of the vapor

${ }^{1}$ Stainless steel sampling container with electropolished interior walls and certified to a cleanliness of $12 \mu \mathrm{g} / \mathrm{m}^{3}$ or $20 \mathrm{ppb}$.

${ }^{2}$ Gas chromatographic separation of organic vapors followed by mass spectrometric identification and quantification of eluting compounds.

${ }^{3}$ Gas chromatographic organic vapor separation followed by quantification of the eluting compounds using a monitor having a flame ionization detector

${ }^{4}$ Pencil-like glass or metal tubes filled with sorbent material 
- Midget impingers (bubblers) ${ }^{1}$ for inorganic vapor analysis.

\subsection{QA OVERSIGHT}

During sampling QA will perform surveillances, where applicable, in accordance with Section 10.4 of the Quality Assurance Manual (QAM), WHC-CM-4-2 (WHC, 1988), and MRP-5.50 of the Management Requirements and Procedures (MRP), WHC-CM-1-3 (WHC, 1988). Specific inspections by QC shall be based upon work packages and shall be documented on a QA Surveillance Plan. Additionally, a calibration check shall be performed to ensure the accuracy of the instruments being used to monitor flammable gas.

The $Q A$ requirements for all onsite laboratories will be implemented in accordance with QAMS-005/80 (EPA, 1983) and applicable QAPPs. Work performed by the subcontractors shall be implemented by a $Q A$ Program that satisfies the requirements of this QAPP. Westinghouse Hanford QA will perform oversight and surveillance of offsite subcontractor activities on vapor analysis.

It is intended that the data collection and analysis of this effort will satisfy several objectives. These include:

- Establish sampling/analysis method validation procedure(s) that will provide required vapor analysis method evaluation data.

- Allow the selection of the best process/methodology for waste tank vapor space characterization.

- Characterize vapor space of waste tank 241-C-103 per WHC-SD-WM-WP-174 (WHC, 1992), "Engineering Work PIan for Tank 241-C-103 Phase I Vapor Phase Characterization, "including the identification of the vapor space hazards posed by flammable and noxious/toxic constituents.

- Establish a vapor space analysis program that can be modified to meet specific characterization needs in the tank farms.

- Establish analyses for the radiological release of samples.

- Modification of existing analytical methodologies to fit the targeted analytes and their concentration.

${ }^{1} \mathrm{~A}$ glass cylinder containing a small volume (15-25 $\left.\mathrm{mL}\right)$ of absorbing solution through which a vapor stream is bubbled. 


\section{WHC-EP-0708 REV. 1}

To accomplish these objectives, the following project tasks have been identified:

- Publish work plans, quality assurance plans, and sampling and analysis procedures that are both method specific and integrated.

- Validate the sampling/analysis procedures.

- Evaluate validated sampling/analysis procedures.

- Design, fabricate, and install required sampling hardware.

- Perform sampling/analysis Readiness Review, where required.

- Sample tank vapor space.

- Ship required samples to subcontractors.

- Prepare and analyze required samples.

- Verify and report sample analysis results.

- Publish Vapor Conference Committee findings and recommendations. 


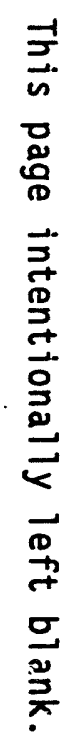

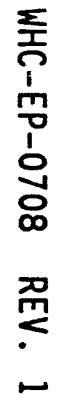

$\stackrel{n}{b}$

. 
WHC-EP-0708 REV. 1

\subsection{PROJECT ORGANIZATION AND RESPONSIBILITY}

The major organizations involved and their responsibilities in the vapor analysis project are identified below:

\subsection{WASTE TANK SAFETY PROGRAMS}

- Provides program direction and interfacing with customers such as, U.S. Department of Energy (DOE), Washington State, Environmental Protection Agency (EPA), etc.

- Evaluates results and determines project direction and milestone tracking for internal control

- Performs program integration with other waste tank safety/characterization projects

- Calculates and reports the results of vapor sampling projects.

\subsection{INDUSTRIAL HYGIENE AND SAFETY}

- Provides oversight for the health and safeiy of workers and guidance of the tank sampling per safety requirement: $:$

\subsection{WHC PROCESSING AND ANALYTICAL LABORATORIES (PAL)}

- Recommends sampling techniques, procedures, and equipment necessary to ensure the DQOs of sampling.

- Responsible for the in-field activities including equipment assembly and testing, sample collection, chain of custody, sample transport, validation of water vapor and radiological analysis, and release for offsite analysis. Samples will be transported to the PAL, PNL 325, and PNL 329 laboratories. PAL will also have responsibility for refrigerated sample storage, refrigerated sample archiving, sample handling and disposal, procurement of new/modified sampling equipment, and training personnel on the sampler system.

- Responsible for interfacing with Tank Farm Operations \& Maintenance to support required sampling equipment fabrication.

- Returns analytical results to Waste Tank Safety Programs point of contact. 
WHC-EP-0708 REV . 1

\subsection{5/329 PNL ANALYTICAL LABORATORIES}

- Performs validation studies, sample container preparation (when required), and sample analyses of specified organic and inorganic compounds. Analyses are performed to PNL impact level 2 or 3 criteria, under the the project QA Program.

- Returns analytical results to Waste Tank Safety Programs point of contact.

\subsection{OREGON GRADUATE INSTITUTE (OGI)}

- Performs method and equipment validation studies per this document.

- Performs method and equipment modifications to analyze selected C-103 organic vapors.

- Performs survey analysis of tank vapors with best available methodologies including estimations of uncertainty.

- Document activities as required by this document (QAPP-013).

- Preparation and certification of SUMMA canisters.

- In cooperation with Sandia NL, return analytical results to Waste Tank Safety Programs point of contact.

\subsection{TANK FARMS OPERATIONS AND MAINTENANCE}

- Responsible for the safety of in-farm activities including installation of the sampling equipment at the tank, providing approved coordination of the sampling with other in-tank activities, scheduling in-farm activities, and ensuring all documentation is in place for sampling.

\subsection{HEALTH PHYSICS}

- Provides radiological safety and support for activities in the tank farms.

\subsection{TWRS QUALITY ASSURANCE}

- Provides program and project support for in-field activity, plus oversight for compliance to requirements for protection of personnel, environment, and facility safety. 
- Performs project assessments and documents compliance with controls to meet regulatory requirements. The $Q A$ role on in-field instruments used to monitor the gas is to ensure that their use, care, and maintenance (including calibration) comply with WHC requirements and manufacturer information.

\subsection{ENVIRONMENTAL DIVISION}

- Provides point of contact to evaluate Federal, State, and DOE environmental compliance requirements and operational guidelines.

- Submits documentation on the program for compliance to National Environmental Protection Act. Issues site-wide reports for compliance to environmental requirements. 
WHC-EP-0708 REV. 1

This page intentionally left blank. 


\subsection{QUALITY ASSURANCE OBJECTIVES FOR MEASUREMENT DATA}

\subsection{INTRODUCTION}

In addition to the usual QA topics that must be addressed in a QAPP per QAMS-005/80 (EPA, 1983), the procedure validation must al so be addressed. The following topics must be defined and discussed:

- Accuracy

- Precision

- Validation

- Completeness

- Comparability

- Representativeness.

Chemical analytical data can be broadly grouped into two categories; namely, quantitative, and qualitative. Qualitative data determines the presence or absence of a compound, element, or ion. Qualitative data usually connotes a bias of greater than $50 \%$. Quantitative data defines the amount of a particular species. Modern analytical chemistry is overwhelmingly a quantitative science and will be applied to the tank targeted characterization.

Errors occur in the quantitation process. They may be bias (systematic) and affect accuracy and, if known, and are not too large and consistent, can be used to correct raw data. The errors may be random which affects the precision. Any resulting data will have an uncertainty due to this type of error. These errors can occur in sampling, sample storage or manipulation, and analytical separation and analysis. Systematic and random errors tend to increase with decreasing amounts of analyte.

Accuracy is determined by the analysis of standards. The standards used to determine accuracy shall be prepared and verified independent from those standards used for calibration purposes.

It is the object of this program to determine the vapor concentration of the targeted analytes to a known level of accuracy and precision (certainty). This means that both the random and systematic errors shall be determined, as best as practically possible, with statistical completeness.

The reduction of quantitative data to qualitative data is based on data importance and the size of both types of errors. For example, quantitative data is frequently identified with an error bias of no more than $50 \%$. Bias can be the difference between percent recovery of a known analyte and 100 . The concept of bias is different from error in that bias, when sufficiently consistent, allows the correction of raw data for this effect. Qualitative data usualiy connotes a bias of greater than $50 \%$. Qualitative data allows the report of major, minor, and trace sample components. A major component would account for $10-99 \%$ of the composition. A minor component would apply to the $0.1-10 \%$ concentration range. Typically a trace component represents $1000 \mathrm{ppm}$ or less. As bias approaches and increases beyond $50 \%$, it generally becomes 
WHC-EP-0708 REV. 1

less consistent and appears more like random error. In circumstances where the methods of analysis are being developed for complex matrices and/or low level target analytes, data quality parameters, developed from initial samples, shall be reported regardless of bias level.

\subsection{MINIMUM QUANTITATIVE LIMITS}

The target quantitative limit (TQL) is the desired concentration that may be reliably quantified to meet the needs of this characterization program with regards to vapor toxicity and flammability. TQL's have been established for toxicity related compounds. Initially, this value has been set at (0.1)X[Threshold Limit Value/8 hour Time Weighted Average (TLV/TWA) for that component]. The value is chosen to allow a margin of error to compensate for inaccuracies and imprecision in the sample analysis and collection. Table $2 \mathrm{~A}$ and $2 \mathrm{~B}$ list the analytes that are currently of highest priority. The tables also show flammability, toxicity, and expected detection limits.

The actual quantitation limits will depend on the vapor characterization technologies used. At present, due to the number and type of compounds to be analyzed, three sample collection techniques will be used. These are (1) SUMMA canister, (2) sorbent tubes, and (3) midget impingers (or bubblers). Several types of sorbent tubes are needed to collect Hydrogen Cyanide (HCN), Ammonia, and Water (both normal and tritiated) vapors. The choice of sorbent type is dependent on the component(s) of interest. Initially, an impinger collection procedure will be used to sample for $\mathrm{HCN}$ and Ammonia. Finally the applicable quatitation limits will depend on the measurement process used. organics will be separated by gas chromatography (GC) followed by measurement with either flame ionization detection (FID) or mass spectrometry (MS). Furthermore, inorganic components will be measured by gravimetry, ion chromatography (IC), or specific ion electrode (SIE).

\subsection{PROCEDURE VALIDATION}

Whenever a sampling and/or an analysis procedure is proposed for a new application, there is a chance that the procedure may not provide the same quality data as in a proven application. Different sample matrices can adversely affect sampling and analytical measurement efficiencies. Thus, procedures need to be validated for new applications. This project has adopted the validation procedure used by the National Institute for occupational Safety and Health (NIOSH). This procedure examines the accuracy and precision values provided by the sampling/analytical procedure for 4-5 concentrations within a specified vapor concentration range for a fixed set of sampling conditions. Ideally, the accuracy and precision values are consistent over the tested concentration range. They all meet prescribed acceptance criteria. NIOSH insists that their procedures, purporting to provide quantitative results, furnish results that are within $25 \%$ of the true concentration for $95 \%$ of the measurements. To meet this accuracy objective, the precision of the measurements must have a Relative Standard Deviation (RSD) of less than 0.105 . To develop the required statistics, a minimum of triplicate samples are run at each concentration level tested. 
WHC-EP-0708 REV. 1

Table 2-A. Analytes of Concern.

\begin{tabular}{|c|c|c|c|}
\hline Compound & $L^{2} L^{a}$ (pprn) & TLV/TWA $(\mathrm{ppm})$ & $M D L^{c}(p p m)$ \\
\hline Dodecane & - & - & - \\
\hline Tridecane & - & - & - \\
\hline Ammonia & 16000 & 25 & 2.5 \\
\hline $\mathrm{NO}, \mathrm{N}_{2} \mathrm{O}$, and $\mathrm{NO}_{2}$ & - & - & - \\
\hline Hexone & 14000 & 50 & 5.0 \\
\hline Vinyl Acetate & 26000 & 10 & 10 \\
\hline Methylene Chloride & 8100 & 50 & 1.0 \\
\hline 1,1 Dichlororethane & - & 200 & 20 \\
\hline Tributyl Phosphate & - & - & - \\
\hline Toluene & 12000 & 100 & 100 \\
\hline Benzene & 14000 & 0.1 & 5.0 \\
\hline Aliphatic Nitriles & - & - & - \\
\hline 1-Butanol & 14000 & 50 & 5.0 \\
\hline Acetone & 21500 & 750 & 75 \\
\hline
\end{tabular}

${ }^{a} \mathrm{LFL}=$ Lower Flammability Limit

${ }^{\mathrm{b}} \mathrm{TLV}=$ Toxicity based on Threshold Limit Value

${ }^{{ }}$MDL $=$Method Detection Limit 
Table 2-B. Analytes of Interest.

\begin{tabular}{|l|c|c|c|}
\hline \multicolumn{1}{|c|}{ Compounds } & LFL (ppm) & TLV/TWA (ppm) & MDL (ppm) \\
\hline Water & N/A & N/A & N/A \\
\hline HCN & - & - & - \\
\hline Carbon Tetrachloride & N/A & 5 & 0.5 \\
\hline Hydrogen & - & - & - \\
\hline Tritium & N/A & N/A & N/A \\
\hline
\end{tabular}

Sampling efficiency will be determined separately from analytical measurement efficiency. Sampling efficiency includes both sample collection/sorption efficiency and sample desorption efficiency. The Vapor Issue Resolution Program initially expects a consistent minimum of $75 \%$ sampling efficiency. In addition, and where justified, sample results shall be corrected for sampling efficiencies that are less than $90 \%$.

\subsection{ACCURACY}

SW-846, (EPA, 1986) defines accuracy in terms of the nearness of a measurement to a true value and evaluates accuracy by determining the percent recovery of a reference sample. Although there have been several attempts to provide simulated reference standards for mixed waste samples, a suitable reference standard does not exist. Thus, accuracy must be evaluated differently. For the Vapor Issue Resolution Program, accuracy is evaluated implicitly. By using simple reference standards, relevant analytical measurement systems are proven to be as error-free as is practically possible. This error-free condition of the analytical measurement system is documented for each batch of samples. No vapor samples may be processed unless the analytical measurement system (AMS) has been proven "in control" by providing an acceptable percent recovery of a simple reference standard. AMS control must be documented for each batch of samples. Analytical accuracies for some methods will be ensured by a Method of Standard Addition which ideally eliminates matrix interferences. When used, the spike added must increase the concentration of the selected analytes to a concentration that is (1) approximately double the original analyte concentration and (2) within the linear range of measurement. The minimization of assignable laboratory errors shall be used to control the analytical data error. In the data quality evaluation, the error attributable to matrix interferences shall be reported in terms of a matrix spike analysis.

There is a special QA concern associated with solid sorbent vapor sampling. Unless care in testing design is taken, it is easy to exceed the capacity of sorbent tube and loose sample due to breakthrough. Because of this each sample in the test array will have a back-up sorbent tube in series with the primary sample cube to prove the adequacy of the test design. The testn design is evaluated by measuring the breakthrough of the analyte in the back-up tube relative to the total amount of analyte recovered. It is 
WHC-EP-0708 REV 。 1

expected that no more than $20 \%$ of each analyte shall be found in the backup tube. The breakthrough shall be documented as part of the data quality evaluation.

\subsection{PRECISION}

SW-846, (EPA, 1986) defines precision as the agreement between a set of replicate measurements and evaluates precision using duplicate or replicate sample analysis. The concept of precision acknowledges that several measurements of a single concentration are expected to occur over a range of values. Ideally, the range of values will be narrow - the more narrow the range, the more precise the measurement. As discussed above in Section 4.2, this requires limiting the RSD to about 0.1 or the Relative Percent Difference (RPD) to 20.

Each test design will include at least one replicate sample which will document precision for the test. Some designs require triplicate samples, others require duplicate samples. Where vapor samples are collected at different levels within a tank, replicate samples will be taken for each level. Wherever possible replicate samples will be collected in parallel, i.e., at the same time, or immediately after one another, at the very least.

\subsection{COMPLETENESS}

The $Q A$ requirement of completeness refers to what extent a project delivered all of the analytical data required by the statement of work for a given sampling job. The Vapor Issue Resolution Program will provide an unconditional minimum of $90 \%$ completeness. The term "unconditional" means that all conditions contributing to the failure of meeting the completeness objective must be discussed as part of the data quality evaluation.

\subsection{REPRESENTATIVENESS}

This objective considers and uses sample extraction and sample handling procedures which minimize changes to the composition of the tank vapors between the time of sample extraction and analysis. There are practical considerations that can adversely affect the representativeness of the vapor sample. For instance, horizontal vapor composition variations will not be measured as samples will be extracted from only one riser. Since vertical vapor composition variations are more probable, early vapor samples shall be drawn from three levels in each tank and vertical variations evaluated. Time and turbulence is expected to eliminate any significant layering of the vapor.

Once extracted the vapor composition may change in the sampling medium as a function of time or temperature. This shall be evaluated as part of the method validation studies. Because of these studies, special sample holding times (between sampling and analysis) and/or sample storage conditions may need to be specified. Initially and until validation studies indicate otherwise, holding times will be set at 60 days. All sampling procedures will include provisions for adequate purging of sampling lines. Purging will ensure the sample lines contain only extracted tank vapor. 


\subsection{COMPARABILITY}

The comparability requirement assures that there will be an acceptable, minimum difference between any two organizations providing vapor sampling data from the same source. One way to evaluate comparability is to compare replicate results from the two organizations and accept some maximum RPD calculated from the mean corresponding to the replicate data. The target value for the RPD for the Vapor Sampling project is \pm 20 .

Both PNL and OGI have been given responsibility for organic analytical method development. While there are no current plans to transfer analytical technology to the 222-S Laboratory, acceptable comparability is expected since (1) the program requires complete documentation of procedure validation and instructions, and (2) analytical procedures will be based on existing, standard lab measurement practices, such as Specific Ion Electrode (SIE), Ion Chromatography (IC), etc. 
WHC-EP-0708 REV. 1

\subsection{VALIDATION OF PROCEDURES}

The validation test procedures must be considered separately for each of the technologies proposed to satisfy the applicable scope of this QAPP.

Validation test results may vary with:

- Changes in major components of the vapor

- Changes in sampling technique, i.e., impinger versus sorbent tube or SUMMA canister

- Changes in sampling conditions, i.e., sample flow rate and temperature

- Changes in the way the sample is presented to the measurement system, i.e. as a mixture versus by separated components or as a concentrated volume versus diluted by some carrier gas

- Changes in measurement system, i.e., Ion Chromatography versus Mass Spectrometry or Specific Ion Electrode

- Changes in sample manipulation, i.e., concentration or dilution, etc.

The five technologies to be discussed are as follows:

- Analysis of organic vapors

- Sample collection by SUMMA canister followed by GC/MS or GC/FID analysis

- Direct GC/FID or GC/TC analysis

- Analysis of inorganic vapors

- Ammonia and HCN--Sample collection by midget bubbler followed Dy SIE or IC analysis

- Water--Sample collection by sorbent trap (Silica Gel) and analysis by Gravimetry

- Tritium--Sample collection by sorbent trap (Silica Gel) and analysis by Liquid Scintilation counting

\subsection{ORGANIC ANALYSIS BY SUMMA CANISTER AND GC/MS OR GC/FID}

The sample collection efficiency for SUMMA canisters is $100 \%$, but there are well documented sample desorption problems. It is well known that polar corpounds adsorb onto the interior surface of the SUMMA and are not quantitatively released when sample volumes are extracted. Because of this sample desorption efficiency must be addressed in the validation procedure. Another sample desorption probkem is that surface adsorbed compounds have been 
known to undergo chemical transformations, involving hydration and oxidation, that change the composition of the vapor as a function of time in the canister. This time effect must also be checked as part of the validation process. Because of these sample desorption problems, the required analytical quantitation shall depend on multiple Matrix Spike Addition (MSA) instead of a series of calibration gas mixtures. In this procedure, spikes of chemically representative compounds at increasing levels will be added to determine the required response factors exclusive of any sample matrix effects. Thus, Validation studies shall address the following SUMMA canister sampling and analysis effects:

- Time in the canister

- Temperature of desorption

- Water vapor content of vapor sample

- Sample concentrating methods

- Level of spike addition

- Equipment operating conditions.

\subsection{ORGANIC ANALYSIS BY DIRECT GC/FID}

There are no sample collection/desorption efficiency problems to be addressed in the validation procedure since the sampling of vapors is direct. The required analytical quantitation will depend on either MSA or by a set of simulated, multi-concentration level, vapor calibration standards. Such standards are readily prepared in special plastic sample bags using a single calibration liquid mixture and the appropriate liquid and gas mixture. Validation studies shall address the following analytical effects:

- Water vapor content of vapor sample

- Sample concentrating methods

- Level of spike addition concentration range of standards

- Instrument operating conditions.

\subsection{AMMONIA AND HCN BY BUBBLER AND SIE}

Both of these gases will be absorbed in a special sorbent solution as the vapor sample is passed through a midget impinger, or bubbler. Ti,e conditions for sample collection are part of a published NIOSH procedure. The vapor sampling for Ammonia and HCN need not be validated if the NIOSH sampling conditions and procedures are used. The required analytical quantitation will depend on MSA.

\subsection{WATER BY SILICA SORPTION AND GAVIMETRY}

While this is not a NIOSH published procedure, it is well documented. As long as the sampling conditions conform to established limits, no additional validation is required. 


\section{WHC-EP-0708 REV. 1}

\subsection{TRITIUM BY SILICA SORPTION AND LIQUID SCINTILATION}

While this is not a NIOSH published procedure, it has been validated by the 222-S Laboratory. As long as the sampling conditions conform to established limits, no additional validation is required. 
WHC-EP-0708 REV. 1

This page intentionally left blank. 


\subsection{SAMPLING PROCEDURES AND SAMPLE PREPARATION}

\subsection{INTRODUCTION}

This section of the QAPP concerns the QA aspects of two different sampling configurations: (1) a vapor/aerosol sampling using a portable sample collection device and an in-tank bubbler array or SUMMA sample tube and (2) a mobile sampling vehicle, designated DML1, capable of collecting SUMMA, solid sorbent or bubbler samples at up to three tank vapor levels. Included in this document is the requirement for procedures that describe the specific sampling techniques outlined in Section 2.0. These procedures shall be subject to revision as knowledge and experience with the techniques is gained over time. Procedural guidance is available from NIOSH publications and ASTM ambient air sampling procedures, such as ASTM D 1357 (ASTM, 1989) and D 3614 (ASTM, 1990).

Sampling procedures will document both the pre- and post-sampling activities. The following sampling activities will be addressed for each of the sampling technologies applicable to this QAPP:

- Cleaning and cleanliness testing of SUMMA canisters

- Reagent preparation and filling of solid sorbent tubes

- Reagent preparation and filling of bubblers

- Cleaning and cleanliness testing of sampling tubing

- Vacuum testing of sampling system

- Applicable sample holding time limit prior to analysis

- Sample line flushing, testing and flushing acceptance criteria

- Sample data recording and calculation requirements

- Field and reagent blank preparation

- Set-up, sample collection, and shut-down operation of portable sample collection device

- Set-up, sample collection, and shut-down operation of DML1

- Post-sample handling, chain-of-custody activities, and sample radioactivity limit verification/documentation for all sampling events.

\subsection{CHAIN-OF-CUSTODY}

As noted above, sample custody will be verified from the sample collection in the field through receipt of the samples by using WHC approved chain-of-custody forms. These forms record the identity of persons in custody of the samples, sample identity, and time and date of transfer of custody. 
The form shall accompany the sample while it is being transported. To verify custody, samples shall be within sight of the persons assigned custody unless the samples are contained in a locked or secured area.

\subsection{FIELD BLANKS}

A final sampling related $Q A$ concern must be addressed - field blanks. Field blanks document the absence of sample contamination from sample containers or reagents brought to the field. Every test plan will include at least one unexposed, composite Reagent Blank for each set of vapor samples. The term "composite" refers to the following three potential sources of contamination. A set of samples are those samples required by both the work plan and this QAPP for a given tank. The Reagent Blank is unexposed in the field. The purpose of the Reagent $B l$ ank is to demonstrate that the sorbent media used in the sampling devices is not contaminated (1) as received from the supplier, (2) by the sample container, (3) or by handling during preparation or field activities. The Reagent Blanks must be unexposed to eliminate sources of contamination either from the sample vapor or the sampling location ambient air. The Reagent Blanks for liquid sorbent media are analyzed directly without extraction. The Reagent Blank for solid sorbent media are analyzed after extraction. Thus, the expected analytical results shall be either (1) below the method detection limit for the analyte in question or (2) below some statistically derived maximum concentration. The Reagent Blank for SUMMA canisters shall also be unexposed in the field. The laboratory will be filled with moist zero gas (MZG) prior to analysis. See procedure T014 (EPA, 1988) for the definition of MZG. The maximum allowed limits for the Reagent $B l$ ank shall be statistically derived. Each reporting laboratory is required to develop, document, and apply acceptance criteria to the Reagent Blank. 
WHC-EP-0708 REV. 1

\subsection{CALIBRATION PROCEDURES AND FREQUENCY}

This section addresses the QA requirements for the calibration of vapor sampling and analysis equipment. The relevant equipment includes (1) sampling temperature and pressure gages and (2) analytical measurement systems. In general all calibrations must be verified as current before sample analysis can be performed. All equipment requiring calibration will be uniquely identified and $\log$ books, or other suitable documentation, will be maintained to record calibration data and, where appropriate, the next required calibration date. Calibration frequencies for analytical measurement systems that differ from the manufacturer's recommendations will be determined by a statistical analysis of calibration check sample results. As long as check standards are within the pre-established acceptance limits, the previous calibration is valid. Reporting laboratories are required to develop, document, and apply acceptance criteria to calibration check results. Any time the system configuration changes for maintenance, the system calibration will be repeated and documented.

Procedures T012 (EPA, 1988) and T014 (EPA, 1988) provide useful guidance for GC/MS and GC/FID calibration information. Applicable calibration, calibration checking, and calculation procedure guidance is also contained in ASTM (ASTM, 1986) and NIOSH publications such as (Taylor, Kupel, 1977), (Busch, Taylor, 1981).

The purity of water and reagents for standards and working solutions should be described in standard operating procedures, or as part of the analysis report. Data producers are required to purchase standards traceable to the National Institute of Science and Technology (NIST), where possible, and to have on file certificates of traceability, where available.

Standards from commercial sources shall be replaced no later than the expiration date supplied by the manufacturer. Reporting laboratories shall develop, document, and apply shelf 1 ife and storage limitations to all calibration standards. 
WHC-EP-0708 REV. 1

This page intentionally left blank. 


\subsection{ANALYTICAL PROCEDURES}

The analysis of all vapor samples within the scope of this QAPP shall be implemented in accordance with the procedures written and approved by the laboratory performing the analysis. These procedures shall meet the following general content requirements:

- Scope

- Applicable reference documents

- Method summary

- Applicability

- Interferences

- Required equipment

- Reagents and materials

- Safety precautions

- Calibration and standardization

- Analysis procedure steps

- Calculations

- Bias (from validation study) and Precision.

Laboratories and sampling operations shall maintain a list of all current procedures, either temporary or permanent, that are being used for the sampling analysis of tank vapor. Temporary procedures need not be detailed or formalized. Project reports will contain notification of procedures revised during the sampling and/or analysis of related vapor samples. 
WHC-EP-0708 REV. 1

This page intentionally left blank. 
WHC,-EP-0708 REV. 1

\subsection{DATA REDUCTION, VALIDATION, AND REPORTING}

\subsection{DATA REDUCTION}

All calculations and unit conversions are confirmed by recomputation and/or review by a second, technically knowledgeable person who did not generate the data. No blank corrections, averaging of duplicates, or other manipulation of data are performed in the laboratory. Any raw laboratory data which is converted from instrument readings to concentration units, by comparison to a standard curve, is accompanied by the standard curve analysis and correlation coefficient, if used. The concentration of standard solutions and instrument readouts are correlated to the desired final report concentration units, so that a minimum of unit conversions is necessary.

Data transcriptions are reviewed and confirmed by the responsible scientist in the laboratory and/or by the manager prior to release of the final data report.

\subsection{DATA VALIDATION}

Laboratory data validation is a continuous process performed at each step of the analytical method. The analyst, responsible scientist, manager, and QA officer all participate in the data validation. The analytical data validation process starts with the verification of sample receipt and continues through approval of the final report. The general steps utilized in laboratory data validation for this project, and the responsible staff, are shown in Table 3 .

The validated data report that the laboratory supplys at the completion of the sample analysis will include the information from the validation review as well as the analysis results.

\subsection{DATA REPORTING}

The report package is prepared after all laboratory analytical data has been compiled and validated. The composition of the complete data package depends on the activities assigned to the reporting unit. The original of the data package is retained by the reporting unit and a legible copy is sent to the data requestor. The composition of the data package shall include the following, as applicable:

- Chain-of-custody records and any field sampling observations and data sheets

- Summary of all non-QC sample analysis results including:

- Sample identification

- ppmr analyte concentration 
Table 3. Laboratory Data Validation Steps.

\begin{tabular}{|l|l|}
\hline \multicolumn{1}{|c|}{ Validation Procedure } & \multicolumn{1}{|c|}{ Responsible Individual } \\
\hline Confirm sample identity & Analyst and scientist \\
\hline $\begin{array}{l}\text { Perform instrument calibration prior } \\
\text { to analytical run }\end{array}$ & Analyst \\
\hline $\begin{array}{l}\text { Perform analysis of check standard } \\
\text { and blank }\end{array}$ & Analyst \\
\hline $\begin{array}{l}\text { Confirms method is in control prior } \\
\text { to analyses of samples }\end{array}$ & Analyst and scientist \\
\hline $\begin{array}{l}\text { Confirm method is in control } \\
\text { periodically during long run }\end{array}$ & Analyst and scientist \\
\hline $\begin{array}{l}\text { For historically unstable analytical } \\
\text { procedures, confirm method is in } \\
\text { control at end of run, perform } \\
\text { initial evaluation of duplicate (or } \\
\text { matrix spike duplicate) and matrix } \\
\text { spike and initiate re-runs as } \\
\text { required }\end{array}$ & Analyst and scientist \\
\hline $\begin{array}{l}\text { Confirm data calculations and } \\
\text { conversions }\end{array}$ & Scientist \\
\hline $\begin{array}{l}\text { Review data for transcription errors } \\
\text { Review accuracy, precision, } \\
\text { completeness, holding times, } \\
\text { detection limits, units and } \\
\text { significant figures }\end{array}$ & Scientist and QA officer \\
\hline $\begin{array}{l}\text { Evaluate data for outliers } \\
\text { Scientist and QA officer }\end{array}$ & Scientist and QA officer \\
\hline
\end{tabular}

- Data quality report that includes the following:

- Average matrix spike recovery for each analyte reported

- Total analytical variance expressed as a relative standard deviation

- Total spatial variance expressed as a relative standard deviation (where applicable)

- Total variance of the mean expressed as a relative standard deviation 


\section{WHC-EP-0708 REV. 1}

- Analyte breakthrough report

- Completeness report.

- $Q A / Q C$ report confirming that:

- Recovery of calibration check standards corresponding to reported data met established acceptance criteria.

- Fresh calibration check standards were prepared at a frequency consistent with established criteria.

- Calibration check standard chemicals were stored under conditions consistent with established criteria.

- Recovery of lab control standards corresponding to reported data met established acceptance criteria.

- Fresh lab control standards were prepared at a frequency consistent with established criteria.

- Lab control standards chemicals were stored under conditions consistent with established criteria.

- Blank(s) analyses met established acceptance criteria.

- Sampling, analysis, calculations and method detection limits were performed or determined by existing (temporary or permanent) written procedures.

- Report explaining necessary procedure deviations and analytical problems

- Report listing method detection limit for each reported analyte 


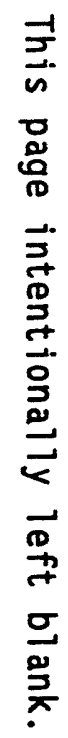

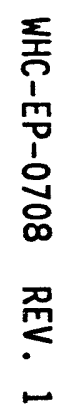


WHC-EP-0708 REV. 1

\subsection{INTERNAL QUALITY CHECKS AND CORRECTIVE ACTION}

\subsection{INTRODUCTION}

Internal quality checks will be performed on the sampling and analytical systems by preparing and analyzing special samples as specified in Section 4.0 of this QAPP. These samples include field blanks, calibration checks, duplicates (or matrix spike duplicates), and matrix spikes. To promote a consistent interpretation of QC sample terminology, Table 4 lists the $Q C$ sample definitions used in this QAPP. The analytical results of these samples determine the quality of tha vapor sampling results. Each set of vapor samples will have a sub-set of corresponding QC samples. The evaluation of these QC sample results determine the quality of the corresponding vapor sample results. Thus, vapor sample results may be evaluated as "quantitative" measurements or "qualitative" estimates. The vapor sample results, whose QC samples satisfy established acceptance criteria, are considered "quantitative."

\subsection{ACCIIRACY RELATED QC CRITERIA}

As rioted above in Section 4.0 of this QAPP, prior to the analysis of any vapor sample, the analytical measurement system must be corfirmed to be "in control." This is demonstrated by verifying that the analytical measurement system responds as expected to (1) lab control standard and (2) a typical calibration standard. The lab control standard is prepared in deionized (DI) water, or other suitable solvent matrix, and has no expected sample matrix interferences. The inability to obtain an acceptable recovery from this standard strongly indicates a serious problem with the analytical measurement system. Any problem(s) must be investigated and resolved prior to using the analytical measurement system to measure vapor samples. The second check standard verifies that the initial, or last, calibration is still valid. Failure to confirm the calibration status, requires recalibration of the instrument prior to quantitative analysis of vapor samples.

If the analytical measurement system can be shown to be "in control," the matrix spike recovery can be used as a measure of the method accuracy.

\subsection{PRECISION RELATED QC CRITERIA}

Data precision is the second half of data quality evaluation. Where vapor samples are extracted from several levels within the tank vapor space, replicate, even duplicate, sample data can be used to calculate (1) the total analytical variance, (2) the total spatial variance and (3) the total variance of the mean. The analytical variance is related to all the processes that take place in the field and laboratory. The spatial variance is related to any existing vapor layering in the tank. The variance of the mean is related to the combined effect of both the analytical and spatial variances. These variances need to be calculated for each reported analyte. 
Table 4. QC Sample Definitions.

\begin{tabular}{|c|c|}
\hline QC Sample Name & Definition \\
\hline Reagent $B$ lank & $\begin{array}{l}\text { This is an artificial sample designed to confirm the absence of } \\
\text { contamination introduced from the sampling container and the sampling } \\
\text { medium. The sample is unexposed to tank vapors but is field handled } \\
\text { during sample labeling activities. SUmMa canisters shall be filled } \\
\text { with moist zero air prior to analysis. Each reporting lab is required } \\
\text { to develop, document, and apply statistical acceptance criteria for } \\
\text { the evaluation of this special sample. }\end{array}$ \\
\hline Preparation Blank & $\begin{array}{l}\text { This is an artificial sample designed to confirm the absence of } \\
\text { contamination from sample preparation chemicals, i.e., solvents, } \\
\text { reagents, etc. This sample is prepared by the analyzing laboratory and } \\
\text { is required to develop; document, and apply statistical acceptance } \\
\text { criteria for the evaluation of this special sample. }\end{array}$ \\
\hline Field surrogate & $\begin{array}{l}\text { This is an artificial sample designed to determine the effect of time } \\
\text { and sample storage conditions on analyte concentration once extracted } \\
\text { from the tank vapor. The sample is prepared by the analyzing } \\
\text { laboratory by adding a concentration of analyte to the absorbing } \\
\text { medium and determining the recovery of the added analyte when the } \\
\text { samples return from the field. Consistent recovery data can be used to } \\
\text { correct calculated results. }\end{array}$ \\
\hline Calibration Check Standard & $\begin{array}{l}\text { This is calibration solution or gas mixture that is designed to verify } \\
\text { that the instrument response factor for a given analyte has not } \\
\text { changed significantly since the-last complete cal ibration. Each } \\
\text { reporting lab is required to develop, document, and apply statistical } \\
\text { acceptance criteria for the evaluation of this special sample. Failure } \\
\text { to meet the acceptance criteria requires a complete recalibration. }\end{array}$ \\
\hline Lab Control Standard & $\begin{array}{l}\text { This is an artificial sample designed to confirm that the analytical } \\
\text { measurement system is "in control". i.e. can accurately measure a } \\
\text { relevant analyte in a simple solution or gas mixture free of matrix } \\
\text { interferences. Typically, these solutions contain one or a few } \\
\text { analytes in a common solvent (DI Water. Methanol, air, etc.). Each } \\
\text { reporting lab is required to develop, document and apply statistical } \\
\text { acceptance criteria for the evaluation of this special sample. Failure } \\
\text { to meet the acceptance criteria requires a shut down of the analytical } \\
\text { measurement system for troubleshooting and/or repairs. }\end{array}$ \\
\hline Matrix Spike & $\begin{array}{l}\text { This is an artificial sample designed to measure the analytical error } \\
\text { due to matrix interferences. The sample is prepared by adding a known } \\
\text { amount of analyte to an aliquot of a field sample. The percent } \\
\text { recovery of the added analyte is determined and reported. By } \\
\text { controlling the non-matrix error (See above), the percent recovery of } \\
\text { this special sample is used as a measure of the method accuracy. }\end{array}$ \\
\hline Matrix Spike Duplicate & $\begin{array}{l}\text { This is an artificial sample designed to measure the method precision. } \\
\text { This sample is a duplicate of the matrix spike sample. A comparison of } \\
\text { the two matrix spike percent recovery values provides the required } \\
\text { evaluation of method precision. }\end{array}$ \\
\hline
\end{tabular}


WHC-EP-0708 REV. 1

\subsection{CONTAMINATION RELATED QC CRITERIA}

Field and Preparation $B 1$ anks are prepared and analyzed to evaluate the presence of contamination from incompletely cleaned sample containers or from improperly prepared reagents. See Section 6.3 for details. By verifying the absence of contamination, via acceptable Field and Preparation Blanks, the use of Matrix Spike Recovery as a measure of method accuracy is further justified. 
WHC-EP-0708 REV. 1

This page intentionally left blank. 


\subsection{PERFORMANCE AND SYSTEM AUdITS}

Vapor sampling will be performed according to the activities found in WHC-SD-WM-WP-174 (WHC, 1992). Tank Farms Environmental or Process Engineering and $Q C$ shall have personnel periodically in the field to ensure that the sampling is performed per the procedures written as part of the experience gained in Phase 1 of this project. In addition, QA personnel may conduct additional surveillance activities for both on and offsite laboratories in accordance with CM-4-2 (WHC, 1988). The purpose of these surveillances will be to verify conformance to unreported QAPP requirements and performance according to established procedures. 
WHC-EP-0708 REV. 1

This page intentionally left blank. 
WHC-EP-0708 REV. 1

\subsection{PREVENTATIVE MAINTENANCE}

The most significant pieces of equipment involved in this effort are the gas chromatographs, the mass spectrometer, and the sampling system purge pump. The rest of the onsite equipment consists mainly of hot water heated sample tubing, electrically operated valves, calibrated gages and meters, and other equipment which can be easily repaired, fabricated, or obtained. Groups responsible for major equipment systems will develop a spare parts 1 ist and maintain the listed spares. A 48-hour availability for these spares is required. 


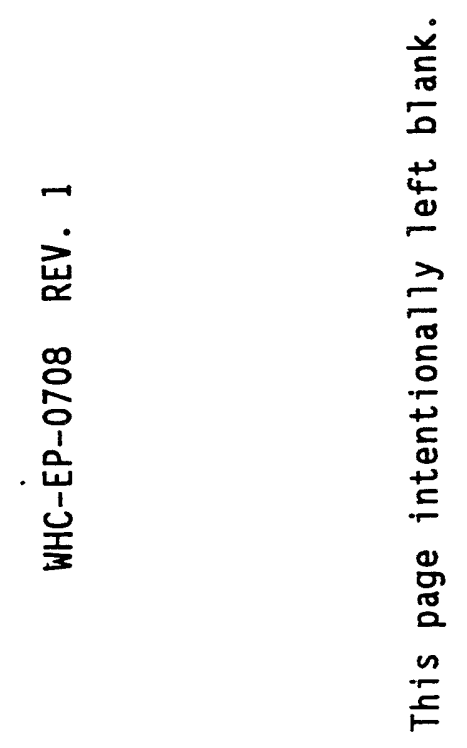


WHC-EP-0708 REV. 1

\subsection{QUALITY ASSURANCE REPORTS TO MANAGEMENT}

Quality assurance will be documented in the data report. This data will meet all data quality objectives presented in this QAPP or it will be qualified with an accompanying explanation of any variances. 
WHC-EP-0708 REV. 1

This page intentionally left blank. 


\section{WHC-EP-0708 REV. 1}

\subsection{REFERENCES}

ASTM, 1986, Recommended Practice for Planning the Sampling of the Ambient Atmosphere, ASTM Procedure D 1357-82, Volume 11.03, American Society for Testing and Materials, Philadelphia, Pennsylvania.

ASTM, 1986, Practice for Evaluating Laboratories Engaged in Sampling and Analysis of Atmospheres and Emissions, ASTM Procedure D 3614-81, Volume 11.03, American Society for Testing and Materials, Philadelphia, Pennsylvania.

ASTM, 1986, Qualification of Measurement Methods by a Laboratory within the Nuclear Industry, ASTM C 1068, American Society for Testing and Materials, Philadelphia, Pennsylvania.

Busch, K. A., and D. G. Taylor, 1977, Chemical Hazards of the Workplace; ACS Symposium Series 149, American Chemical Society, Washington, D.C.

EPA, 1983, Interim Guidelines and Specifications for Preparing Quality Assurance Plans, QAMS-005/80, U.S. Environmental Protection Agency, Washington, D.C.

EPA, 1986, Test Methods for Evaluating Solid Waste, SW-846 Rev. U, U.S. Environmental Protection Agency, Washington D.C.

EPA, 1988, Compendium of Methods for the Determination of Toxic Organic Compounds in Ambient Air, EPA/600/4-89/017, U.S. Environmental Protection Agency, Research Triangle Park, North Carolina.

Taylor, D. G., R. E. Kupel, and J. M. Bryant, 1977, Documentation of the NIOSH Validation Tests, DHEW (NIOSH) Publication No. 77-185, Cincinnati, Ohio.

WHC, 1988, Management Requirements and Procedures, WHC-CM-1-3, Westinghouse Hanford Company, Richland, Washington.

WHC, 1988, Quality Assurance Program Manual, WHC-CM-4-2, Westinghouse Hanford Company, Richland, Washington.

WHC, estimated 1992, Engineering Work Plan for Tank 241-C-103 Phase 1 Vapor Phase Characterization, WHC-SD-WM-174, Rev. 0, Westinghouse Hanford Company, Richland, Washington.

WHC, 1993, Engineering Work Plan for Aerosol and Vapor Sample Collection in Tank 241-C-103, WHC-SD-WM-WP-198, Rev. 0, Westinghouse Hanford Company, Richland, Washington.

WHC, 1993, Engineering Work Plan for Tanks 241-BY-104, 105, 106 Vapor Phase Characterization, WHC-SD-WM-WP-223, Rev. 0, Westinghouse Hanford Company, Richland, Washington. 


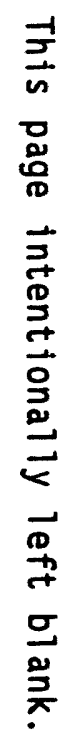

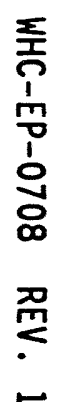


WHC-EP-0708 REV. 1

\section{DISTRIBUTION}

\section{Number of copies}

\section{OFFSITE}

2

U.S. Department of Energy 1000 Independence Ave SW EM-36

Washington, D.C. 20585

Kenneth Lang Charles O'Dell

U.S. Department of Energy 1000 Independence Ave SW EM-35

Washington, D.C. 20585

\section{Corn}

32

Charles S. Abrams 1987 Virginia Idaho Falls, ID 83404

David 0. Campbel1 (1) 102 Windham Road

Oak Ridge, TN 37830

Fred N. Carlson (1) 6965 North 5 th West Idaho Falls, ID 83401

Air Products and Chemicals 7201 Hamilton Blvd Allentown, PA 18195-1501

George E. Schmauch 


\section{WHC-EP-0708 REV. 1}

\section{DISTRIBUTION (continued)}

\section{OFFSITE}

1

Ames Laboratory

Room 107, Spedding $\mathrm{Hall}$

Ames, IA 50011

G. Junk, c/o M. Forsling

2

Brookhaven National Laboratory

Upton, NY 11973

Morris Reich (2)

1

Harvard School of Public Health

665 Huntington Ave

Bldg 1, Rm G-1

Boston, MA 02115

Melvin W. First

1

Waste Policy Institute

555 Quince Orchard Road

Gaithersburg, Maryland 20872-1437

Donald T. Oakley

1

NUCON

7000 Huntley Road

P.0. Box 29151

Columbus, $\mathrm{OH} 43229$

J. L. Kovach

Northwest Instrument Systems, Inc. 3100 George Washington Way

Richland, WA 99352

M. Story 
WHC-EP-0708 REV. 1

\section{DISTRIBUTION (continued)}

\section{OFFSITE}

1

Oak Ridge National Laboratory

P. 0. Box 2008

MS-6495

Oak Ridge, TN 37831

Charles W. Forsberg

1

Oregon Graduate Institute of Science \& Technology $19000600 \mathrm{NW}$ Von Neuman

Beaverton, OR 97006

R. Rasmussen

1

Oak Ridge National Laboratory

Analytical Chemistry Division

P.0. Box 2008

Oak Ridge, TN 37831

Roger A. Jenkins

Sandia National Laboratory

Building 823

1515 Eubank S.E.

Albuquerque, NM 87123

L. Bustard

W. Einfeld

Science Applications International Corporation 12850 Middlebrook Road

Trevion I, Suite 300

Germantown, MD 20874

Ray S. Daniels (3) 


\section{WHC-EP-0708 REV. 1 \\ DISTRIBUTION (continued)}

\section{ONSITE}

10

U.S. Department of Energy, Richland Operations office

R. F. Christensen (8)

R. E. Gerton

A4-02

Public Reading Room

A4-02

Al-65

Pacific Northwest Laboratory

T. R. Clauss

P8-08

J. S. Fruchter

S. C. Goheen

B. M. Johnson (3)

B. D. Lerner

K6-96

P8-08

$\mathrm{K} 1-78$

R. B. Lucke

P8-08

PNL Technicaì Files

P8-08

$\mathrm{K} 1-11$

Westinghouse Hanford Company

H. Babad

R2-31

J. R. Bell

R3-09

M. L. Bell

T6-16

R. J. Blanchard

$\mathrm{R} 1-17$

B. Conrad

H5-09

C. DeFigh-Price

B4 -55

J. C. Fulton

K. A. Gasper

J. M. Grigsby

D. J. Hart

J. L. Huckaby

M. N. I slam

R2-31

R2 -08

$\mathrm{H} 5-32$

R3 -54

R2 -78

R3 -08

C. A. Kuhlman

B3-30

T. L. Moore

H5 -09

J. W. Osborne (10)

R2-78

I. E. Reep

T. P. Rudolph

R2-08

M. H. Shannon

R3 -54

C. D. Suydam

H5 -30

S1-57 

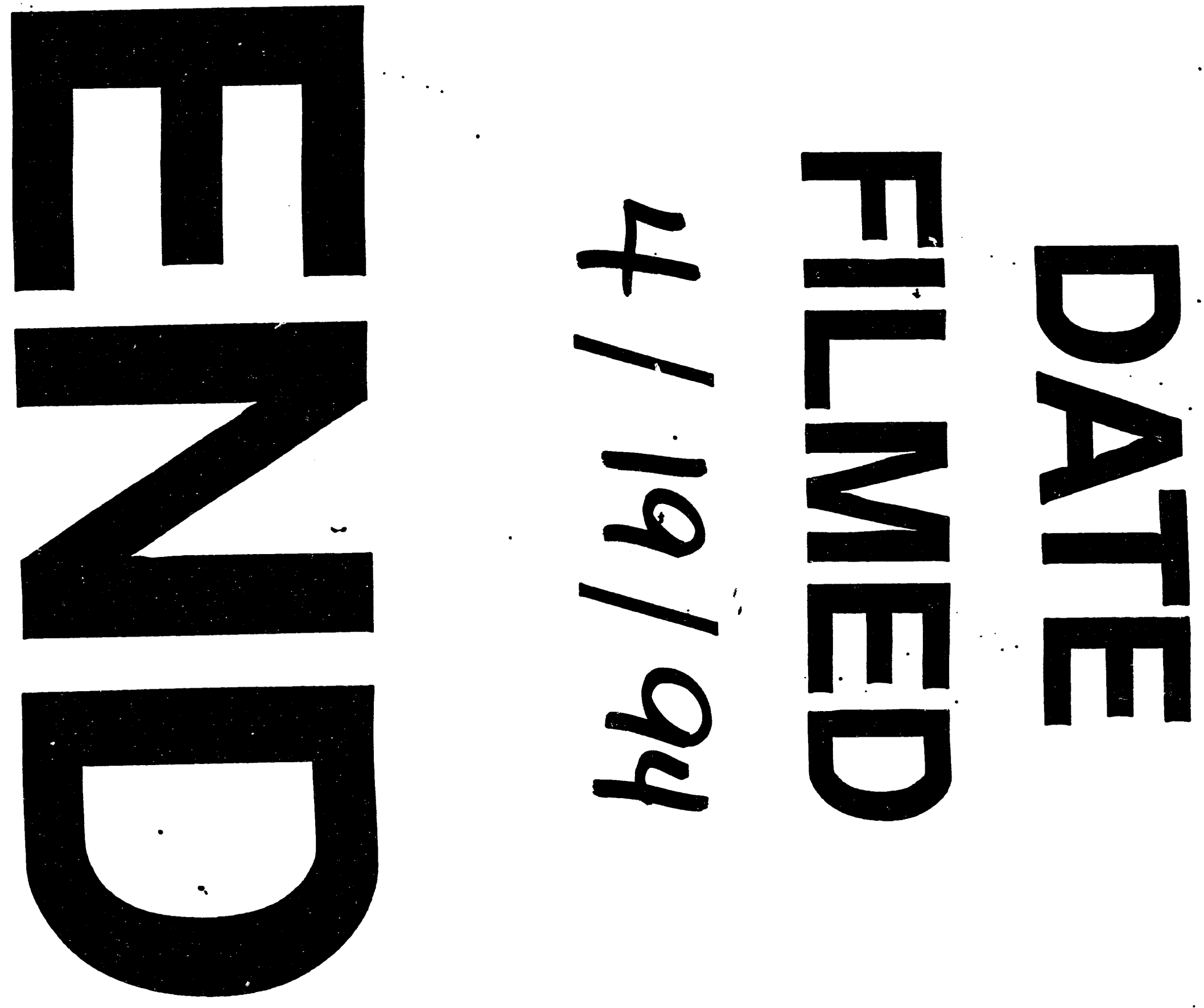


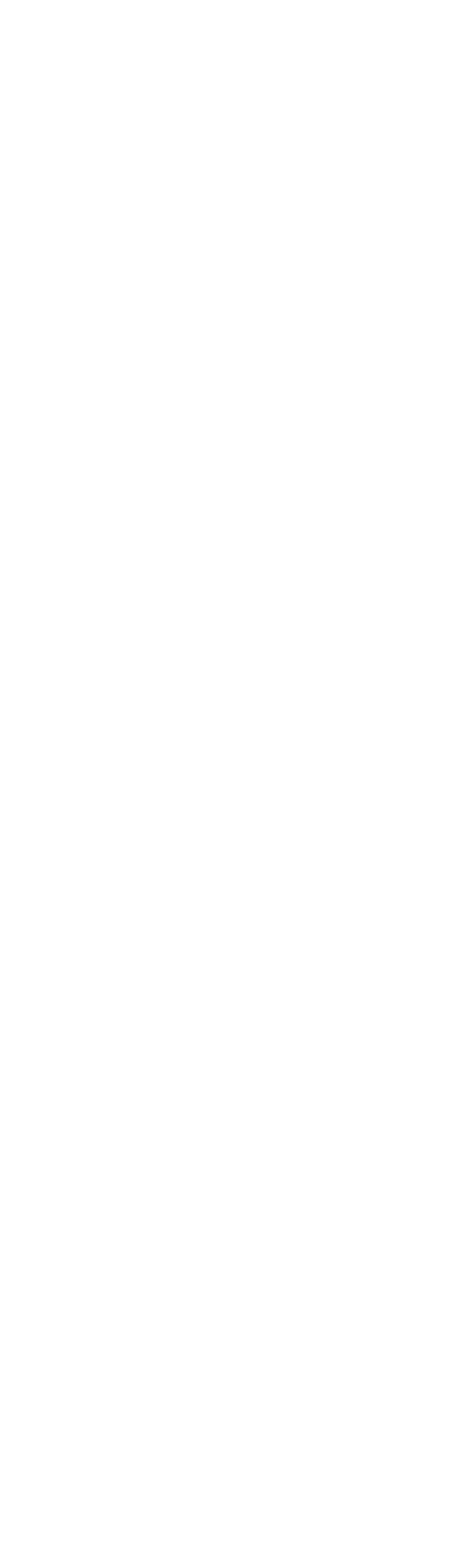

